\title{
SELEKSI KASUS DAN PERAWATAN ORTODONTIK PADA GIGI KANINUS MAKSILA IMPAKSI
}

\author{
Handoko Setiawan* \& Prihandini** \\ * Program Studi Ortodonsia, Program Pendidikan Dokter Gigi Spesialis, \\ Fakultas Kedokteran Gigi, Universitas Gadjah Mada, Yogyakarta \\ ** Bagian Ortodonsia, Fakultas Kedokteran Gigi, Universitas Gadjah Mada, Yogyakarta
}

\section{ABSTRAK}

Latar Belakang : Seleksi kasus merupakan hal utama sebelum melakukan perawatan ortodontik terhadap gigi kaninus maksila impaksi. Hanya gigi kaninus maksila impaksi yang erupsi ke bidang oklusal dan berada di ruangnya yang dapat dilakukan perawatan ortodontik. Konsultasi kepada Ahli Bedah Mulut mengenai teknik surgical exposure akan memberikan manfaat bagi Ortodontis dalam melakukan perawatan ortodontik. Teknik pembedahan yang tepat akan membuat proses perawatan ortodontik lebih singkat dengan hasil memuaskan. Teknik Begg merupakan salah satu teknik ortodontik yang dapat digunakan untuk merawat gigi kaninus impaksi. Tujuan: Memaparkan teknik perawatan ortodontik dengan alat cekat teknik Begg pada gigi kaninus maksila impaksi yang erupsi ke bidang oklusal. Kasus : Perempuan 18 th disertai gigi kaninus maksila kanan impaksi. Perawatan: 1. Perawatan ortodontik dengan teknik Begg tahap pertama. 2. Surgical exposure oleh Ahli Bedah Mulut. 3. Perawatan ortodontik teknik Begg tahap kedua dan ketiga. Kesimpulan: Perawatan orotodontik dengan teknik Begg mampu menempatkan gigi kaninus impaksi pada lengkung gigi yang baik. Maj Ked Gi; Desember 2011; 18(2): 152-155

Kata kunci: Gigi kaninus impaksi, teknik Begg

\section{ABSTRACT}

Background: Case selection is the important thing before orthodontically impacted maxillary canine treated. Certain impacted maxillary canine that erupts to occlusal plane could be orthodontically treated. Consultation to Oral Surgeon to have a proper surgical exposure technique would be benefit to speed up the treatment with a successful outcome. Begg Technique is a choice of orthodontic treatments that could treat impacted maxillary canine. Purpose: To describe of Begg technic for treating of impacted maxillary canine that erupts to occlusal plane. Case: A 18 years old female patient with impacted of a right maxillary canine. Management: 1. First step of Begg technic. 2. Surgical exposure by Oral Surgeon. 3. Second and third steps of Begg technic. Conclusion: Begg technique could treat impacted maxillary canine in to the proper maxillary arch jaw. Maj Ked Gi; Desember $2011 ; 18(2): 152-155$

Keywords: Impacted maxillary canine, Begg technique

\section{PENDAHULUAN}

Gigi impaksi adalah gigi permanen yang tertanam di dalam tulang alveolar karena terhalang oleh gigi lain, tulang atau jaringan lunak sehingga proses erupsinya terhambat. Gigi kaninus merupakan gigi kedua yang seering mengalami impaksi setelah gigi molar ketiga. Frekuensi impaksi gigi kaninus adalah $0,8-2,8 \%$ dan sering terjadi pada perempuan dibandingkan pada laki-laki. Impaksi gigi kaninus, 18 hingga 20 kali lebih banyak dijumpai pada maksila dibandingkan pada mandibula dan $\pm 85 \%$ terletak di bagian palatal lengkung gigi. ${ }^{1}$

Lokasi gigi kaninus impaksi dapat diketahui melalui foto rontgen periapikal, anteroposterior, oklusal dan ekstraoral. Mengetahui lokasi gigi impaksi berguna untuk menentukan teknik surgical exposure. Tiga macam teknik surgical exposure untuk pembukaan gigi kaninus impaksi adalah: excisional uncovering, apically poisitioned flap dan closed eruption technic. Memilih teknik yang tepat dapat mencegah dan mengurangi kerusakan berlebihan pada jaringan periodontal gigi yang akan dirawat secara ortodontik. $^{2}$

Perlu dilakukan seleksi kasus sebelum melakukan perawatan ortodontik terhadap gigi kaninus maksila impaksi, karena tidak semua gigi kaninus impaksi dapat dipandu erupsinya ke dalam lengkung gigi yang baik, bergantung pada arah erupsi gigi tersebut. Arah erupsi gigi impaksi ke bidang oklusal, bersudut tidak lebih dari $45^{\circ}$ terhadap garis median wajah, terletak di sisi distal insisivus lateral dan tidak ada ankilosis mempunyai prognosis yang baik untuk dilakukan perawatan ortodontik. Hasil perawatan ortodontik terhadap gigi kaninus maksila impaksi juga dipengaruhi oleh motivasi \& tingkat kepatuhan penderita terhadap instruksi perawatan, kesehatan mulut secara menyeluruh dan usia penderita. Usia optimal untuk perawatan gigi kaninus maksila impaksi adalah usia remaja . ${ }^{1}$

Etiologi gigi impaksi dapat disebabkan oleh faktor primer dan faktor sekunder. Faktor primer meliputi keterlambatan resorpsi dan trauma pada benih gigi sulung, gangguan jalannya erupsi gigi per- 
manen, kecukupan ruang untuk erupsi, adanya rotasi pada benih gigi, prematur loss gigi sulung dan erupsi gigi kaninus ke dalam celah pada penderita celah langit-langit. Faktor sekunder meliputi abnormalitas kekuatan otot, febrile disease, gangguan endokrin, dan defisiensi vitamin D. ${ }^{3}$ Beberapa hal juga diperkirakan menjadi etiologi gigi kaninus impaksi yaitu: benih gigi kaninus maksila memiliki jalan erupsi terpanjang dibandingkan gigi lain, adanya peg shaped gigi insisivus lateral dan ankilosis. ${ }^{4}$

Perawatan gigi kaninus impaksi memerlukan kerjasama antara Ahli Bedah Mulut dan Ahli Ortodontik. Ahli Ortodontik bekerja melakukan seleksi kasus, menentukan prognosis dan memandu erupsi gigi impaksi ke dalam lengkung yang baik, sedangkan Ahli Bedah Mulut melakukan surgical exposure agar braket dapat dibonding pada gigi . Teknik surgical exposure yang baik dapat mempermudah prores erupsi gigi impaksi yang dapat mempengaruhi lama proses penyelesaian perawatan ortodontik. Hasil perawatan ortodontik dengan estetika yang baik dan stabilitas yang tinggi juga dipengaruhi oleh teknik surgical exposure selain teknik ortodontiknya sendiri. ${ }^{5}$

Traksi ortodontik untuk memandu arah erupsi gigi kaninus impaksi dapat dilakukan setelah terjadi penyembuhan luka akibat surgical exposure. Teknik direct bonding dengan menempelkan braket atau lingual button pada gigi impaksi untuk keperluan traksi ortodontik dinilai lebih baik dibandingkan dengan ligasi kawat pada servik gigi impaksi. Teknik direct bonding dapat mencegah loss of attachment pada cemento enamelo juntion terhadap gigi impaksi yang dipandu arah erupsinya. ${ }^{6}$

Memberikan gaya berlebihan pada saat traksi gigi impaksi akan menyebabkan gangguan sirkulasi darah dan meningkatkan aktivitas sel odontoblast pada pulpa, hal ini harus diperhatikan oleh Ahli Ortodontik agar tidak terjadi nekrosis pada gigi. ${ }^{7}$ Gaya ringan sebesar 20-60g dapat diaplikasikan untuk keperluan traksi gigi kaninus impaksi menuju lengkung yang baik, traksi dapat dilakukan dengan karet elastik ataupun ligarute wire. ${ }^{2}$

Pemanduan erupsi gigi kaninus impaksi dapat dilakukan dengan perawatan ortodontik cekat atau semi cekat. Salah satu teknik perawatan ortodontik cekat adalah teknik Begg, teknik ini merupakan teknik ortodontik dengan gaya ringan dalam menggerakkan gigi. Gaya ringan yang dihasilkan oleh teknik Begg menjadikan teknik ini sebagai teknik ortodontik yang terpilih untuk merawat gigi kaninus maksila impaksi. Proses perawatan pada teknik Begg mengikuti kaidah umum, yaitu: mengikuti kaidah tiga tahap perawatan. Tahap pertama merupakan tahap levelling dan unravelling. Tahap kedua merupakan space closing. Tahap ketiga adalah tahap finishing yaitu proses paralelling akar gigi. ${ }^{8.9}$

\section{LAPORAN KASUS}

Pasien perempuan, umur 18 tahun datang ke klinik Ortodonsia RSGM Prof. Soedomo dengan keluhan gigi taring rahang atas kanan tidak tumbuh sehingga pasien terlihat ompong dan terganggu penampilannya. Pemeriksaan intraoral menunjukkan gigi kaninus maksila kanan tidak tumbuh dan terlihat ruang yang cukup untuk penempatan gigi kaninus (Gambar 1). Terdapat celah antara gigi anterior maksila bagian kiri, gigi insisivus lateral kiri merupakan peg tooth. Bentuk lengkung rahang atas dan bawah adalah setengah elips dan ukuruan lidah sedang. Hubungan molar kanan kelas 1 Angle dan garis tengah tidak segaris. Garis tengah intersinsisiv terhadap garis tengah rahang bergeser dua $\mathrm{mm}$ ke kanan (Gambar 2).

Analisis hasil foto rontgen lateral dengan teknik shift scetch method menunjukkan gigi kaninus maksila bagian kanan mengalami impaksi di bagian palatal, mahkota gigi kaninus impaksi berada di sisi distal apeks gigi insisivus lateral dan arah pertumbuhan gigi adalah $\pm 45^{\circ}$ terhadap garis median wajah (Gambar 3). Apeks akar gigi kaninus impaksi terlihat bengkok ke mesial.

\section{Rencana Perawatan}

Berdasarkan analisis terhadap foto rontgen lateral dan panoramic maka dapat ditentukan prognosis perawatan ortodontik gigi kaninus impaksi pada kasus ini adalah baik. Rencana perawatan disusun dengan tujuan memandu arah erupsi gigi kaninus impaksi ke dalam lengkung gigi yang baik, yaitu: 1. Merujuk penderita kepada Ahli Bedah Mulut untuk perencanaan teknik surgical exposure; 2. Perawatan ortodontik teknik Begg tahap pertama sebagai persiapan anchorage untuk traksi gigi kaninus impaksi; 3. Surgical exposure oleh Ahli Bedah Mulut; 4. Traksi gigi kaninus impaksi; 5 . Perawatan ortodontik tenik Begg tahap kedua dan ketiga.

\section{Tahapan Perawatan}

Dilakukan perawatan ortodontik berdasarkan pada teknik Begg. Perawatan dimulai dengan tahap pertama yang bertujuan mengatur posisi gigi melalui koreksi buko-lingual (unravelling) dan memperbaiki ketidakteraturan dalam arah vertikal (levelling). Tahap pertama akan menghasilkan susunan gigi-geligi yang teratur di dalam lengkung yang baik, kondisi tersebut akan berfungsi sebagai anchorage yang kuat pada saat dilakukan traksi terhadap gigi kaninus impaksi. Perawatan tahap pertama dimulai dengan menggunakan busur kawat berdiameter 0,014 hingga 0,018 inch. Besar anchorage bend adalah $15^{\circ}$. Setelah didapatkan kondisi anchorage yang kuat, penderita dirujuk kepada Ahli Bedah Mulut untuk di- 
lakukan surgical exposure. Biasanya dua minggu setelah surgical exposure, perawatan ortodontik dapat dilanjutkan. Traksi gigi kaninus ke dalam lengkung dilakukan dengan menambahkan gaya setiap dua minggu pada kawat ligatur diameter 0,001 inch yang dikaitkan pada lingual button di gigi kaninus impaksi dan crimpable hook pada busur kawat 0,018 inch.

Tahap kedua bertujuan untuk space closing, pada kasus ini tidak dilakukan karena tidak ada pencabutan gigi. Tahap ketiga tidak dilakukan palatal root torque karena posisi gigi-geligi sudah baik, tahap ketiga pada kasus ini bertujuan mempertahankan lengkung gigi ideal dengan menggunakan plain archwire 0,018 inch dengan anchorage bend $15^{\circ}$ di mesial molar pertama, circle hook pada mesial braket kaninus. Setelah melewati tahap ketiga, dilanjutkan dengan pemakaian retainer.

\section{PEMBAHASAN}

Keberhasilan perawatan ortodontik gigi kaninus impaksi tergantung dari berbagai faktor, antara lain: usia dan motivasi penderita, besar ruang yang tersedia untuk erupsi gigi, posisi gigi impaksi terletak pada sisi distal gigi insisivus lateral, sudut mahkota gigi terhadap garis median wajah. Pada kasus ini, gigi impaksi tumbuh ke arah oklusal dengan sudut tidak lebih dari $45^{\circ}$, tersedia ruang yang cukup untuk erupsi, gigi impaksi berada di sebelah distal gigi insisivus lateral dan motivasi tinggi dari penderita. Empat hal tersebut menjadikan kasus ini dapat dilakukan perawatan ortodontik dengan prognosis baik. ${ }^{1}$

Hasil analisis foto rontgen periapikal dengan teknik Shift Scetch method menunjukkan gigi kaninus impaksi terletak di bagian palatal dengan mahkota gigi berada di sisi distal apeks insisivus lateral. Setelah mempertimbangan beberapa resiko pembedahan, maka Ahli Bedah Mulut memutuskan melakukan surgical exposure dari sisi bukal dengan closed eruption technic. Surgical exposure dari sisi bukal memiliki resiko pembedahan minimal dan closed eruption technic menghasilkan pembukaan lebih luas pada mahkota gigi impaksi. Mahkota gigi impaksi yang terpapar lebih luas memberikan beberapa keuntungan bagi Ahli Ortodontik yaitu: dapat dilakukan direct bonding, pekerjaan traksi ortodontik menjadi lebih lebih mudah serta lebih nyaman bagi penderita (Gambar 4$){ }^{5}$

Proses traksi gigi kaninus ke dalam lengkung gigi pada kasus ini membutuhkan waktu tujuh bulan dan waktu yang dibutuhkan untuk mencapai fase retensi adalah 19 bulan. Untuk mendapatkan hasil perawatan yang stabil, braket tetap dipakai dalam kondisi pasif hingga tujuh bulan kemudian, sehingga total waktu yang dibutuhkan untuk melepas braket dan memakai alat retainer adalah 26 bulan.
Untuk mempertahankan kesimetrisan lengkung rahang kiri dan kanan, celah sebesar tiga $\mathrm{mm}$ antara gigi insisivus sentral kiri dan insisivus lateral kiri tetap dijaga keberadaanya selama perawatan ortodontik. Setelah selesai perawatan ortodontik dilakukan perbaikan peg shaped gigi insisivus lateral dengan jaket berbahan komposit (Gambar 5a).

Gingivitis mudah terjadi pada saat perawatan ortodontik dikarenakan penumpukan plak pada gingiva, tetapi hal ini biasanya tidak menyebabkan kerusakan tetap..$^{10}$ Penderita pada kasus ini juga sering mengalami gingivitis dan ulkus pada mukosa, terutama pada awal traksi ortodontik, tetapi dengan menghilangkan plak dibantu dengan berkumur larutan antiseptik, penderita tetap bersemangat melanjutkan perawatan. Didapatkan kondisi normal pada jaringan periodontal gigi kaninus impaksi setelah perawatan ortodontik. Penilaian yang dilakukan adalah derajad luksasi gigi dan kedalaman gingiva tepi. Test vitalitas gigi menunjukkan gigi hasil perawatan ortodontik adalah vital dengan apeks gigi tidak mengalami resorpsi (Gambar 6).

\section{KESIMPULAN}

Seleksi kasus perlu dilakukan sebelum memulai perawatan ortodontik terhadap gigi kaninus maksila impaksi karena tidak semua gigi kaninus maksila dapat dipandu erupsinya ke dalam lengkung yang baik. Perawatan ortodontik dengan teknik Begg dapat memandu erupsi gigi kaninus impaksi ke dalam lengkung yang baik.

\section{DAFTAR PUSTAKA}

1. McSherry P \& Richardson A: Ectopic eruption of the maxillary cannine quantified in three dimensions on cephalometric radiographs between the ages of 5 and 15 years. Eur J Orthod 1999;21:41-8.

2. Bishara SE, Kommer DD, McNeil MH, Montagano LN, Oesterle LJ, \& Youngquist WY:Management of impacted canines. Am J Orthod 1976;69:371-387.

3. Jacoby $\mathrm{H}$ : The etiology of maxillary canine impactions. Am J Orthod 1983;84:125-132.

4. McSherry $P$ \& Richardson A:The Ectopic eruption of the maxillary cannine: A Review. Br J Orthod 1998;25:209-16.

5. Kokich VG: Surgical and Orhodontic Management of Impacted Maxillary Canines, Am J Orthod 2004; 126: 278-83.

6. Hansson C \& Rindler A:Periodontal Conditions Following Surgical and Orthodontic Treatment of Palatally Impacted Maxillary Canines - a Follow-up Study. Angle Orthod 1998; 68: 167-76.

7. Woloshhyn H, Artun J, Kennedy DB, \& Joondeph DR: Pulpal and Periodontal Reactions to Orthodontic Alignment of Palatally Impacted Canines. Angle Orthod 1994; 64: 257-64. 
8. Begg PR \& Kesling PC: Begg Orthodontic Theory and Technique. $2^{\text {nd }}$ W.B. Saunders Co. Philadelphia. 1977:162-3.

9. Fletcher GGT:The Begg Appliance and Technique. John Wright \& Sons (print) Ltd. Briston. 1981:15-48,82-94.

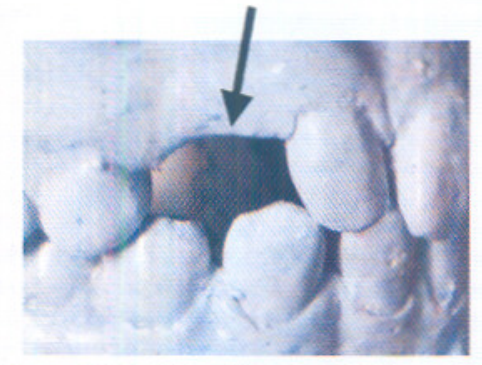

Gambar 1. Tersedia ruang yang cukup untuk erupsi gigi kaninus impaksi.

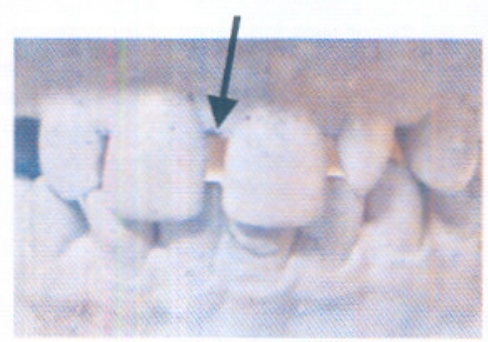

Gambar 2. Garis tengah interinsisiv bergeser dua $\mathrm{mm}$ ke arah kanan.

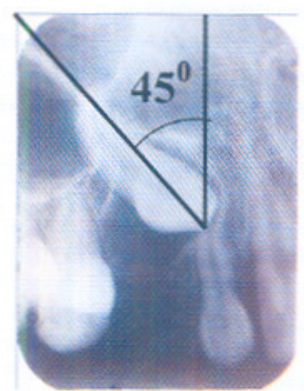

Gambar 3. Gigi impaksi erupsi ke arah bidang oklusal bersudut 450 terhadap garis median wajah dan berada di sisi distal gigi insisivus lateral

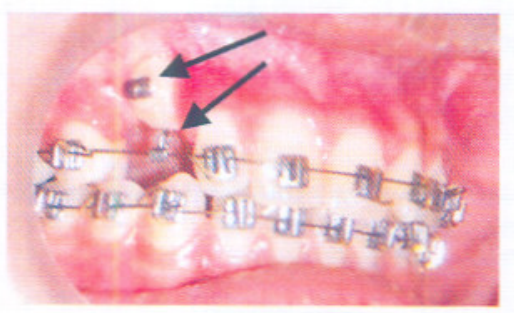

Gambar 4. Foto intraoral, setelah tiga bulan surgical exposure. Lingual button pada gigi kaninus impaksi dan crimpable hook pada kawat busur.
10. Wisth PJ, Norderval K, \& Bøe OE:Periodontal Status of Orthodontically Treated Impacted Maxillary Canines. Angle Orthod 1976; 46: 69-76.

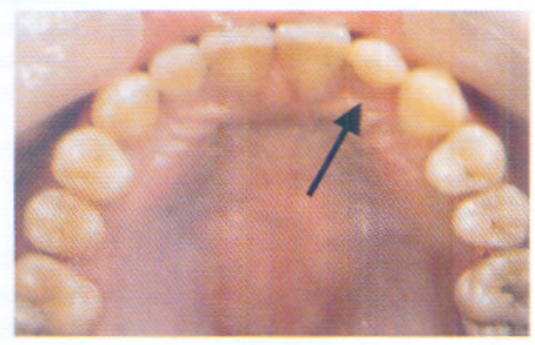

(5a)

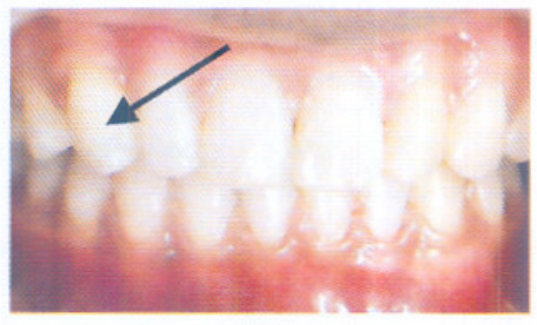

$(5 b)$

Gambar 5. Foto intraoral setelah 26 bulan perawatan.a. Gigi insisivus lateral kiri diberi mahkota jaket berbahan komposit. b. Gigi hasil perawatan tidak mengalami nekrosis, derajad luksasi gigi dan kedalaman gingiva tepi normal.

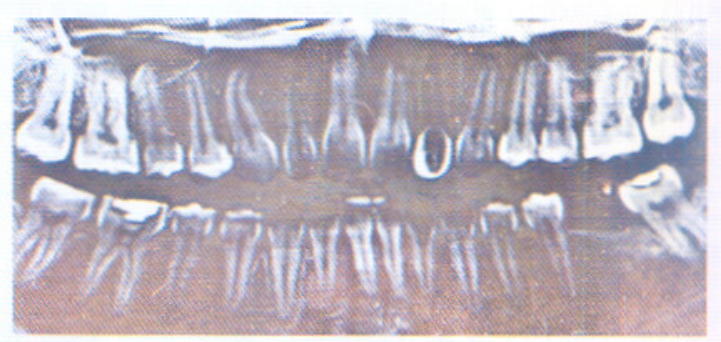

Gambar 6. Foto rontgen pasien setelah selesai perawatan (26 bulan). Tidak terjadi resorpsi akar dan pelebaran jaringan periodontal pada gigi kaninus setelah perawatan ortodontik 